\title{
INFLUENCE OF ULTRAVIOLET IRRADIATION ON THE GROWTH OF BACTERIA AND ARNDT-SCHULTZ LAW
}

\author{
TAdatoshi MASUYAMA, SAdao KOBAYASHI AND \\ Atsushi OTANI
}

The National Institute of Health, Tokyo

(Received: July 20th, 1953)

\section{INTRODUCTION}

Regarding the influence of ultraviolet irradiation on the growth of bacteria, numerous studies have been accomplished and it has been known that there exists a relation of exponential function between the bactericidal effect and the amount of ultraviolet ray irradiated. The methods employed in those studies,1),2),3),4) a,b, however, are mostly so called plate method in which the irradiation is made on ordinary agar plates inoculated with a known quantity of bacteria.

We prepared a bacterial suspension of $E$. coli using physiological saline as its dispersion medium. Placing the suspension in quartz tubes, ultraviolet irradiation was applied to determine $50 \%$ survival time. The survival time thus determined was found to differ considerably from the one determined by plate method in which the same bacterial suspension was used5). Thus, our attention was directed to the broth which was the chief component of the agar plate. A bacterial suspension was prepared using the broth as its dispersion medium. Upon investigation the survival curve and the biological characters of the survival bacteria after irradiation made on this suspension, extremely interesting facts were observed.

\section{EXPerimental Method AND Findings}

All experiments were carried out under the same conditions stated below:

Light source: $15 \mathrm{~W}$ low pressure quartz mercuric lamp (2537 $\AA$ approximately $90 \%$ and the lamp was switched on 30 minutes prior to the use)

Irradiation distance: $50 \mathrm{~cm}$ (the energy at a distance of $50 \mathrm{~cm}$ was $195 \mu \mathrm{w} / \mathrm{cm}^{2} / \mathrm{sec}$ by $100 \mathrm{~V} 420 \mathrm{~mA}$ )

Irradiation temperature: $22-25^{\circ} \mathrm{C}$

Irradiation humidity: $\mathbf{7 0 - 7 5 \%}$

Quartz tube: thickness, $1.5 \mathrm{~mm}$; inside diameter, $14 \mathrm{~mm}$; length, $120 \mathrm{~mm}$

Dispersion medium: broth (the optical density of a 1:100 dilution was 0.562 by Beckman's spectrophotometer at $2537 \AA$ and the same broth was used throughout the present experiments)

Bacterial suspension: Escherichi coli communis $C-13$ cultured at $37^{\circ} \mathrm{C}$ for 24 hours was washed with physiological saline for 3 times. A suspension 
Fig. 1. Absorption spectra of ultraviolet light irradiated broth

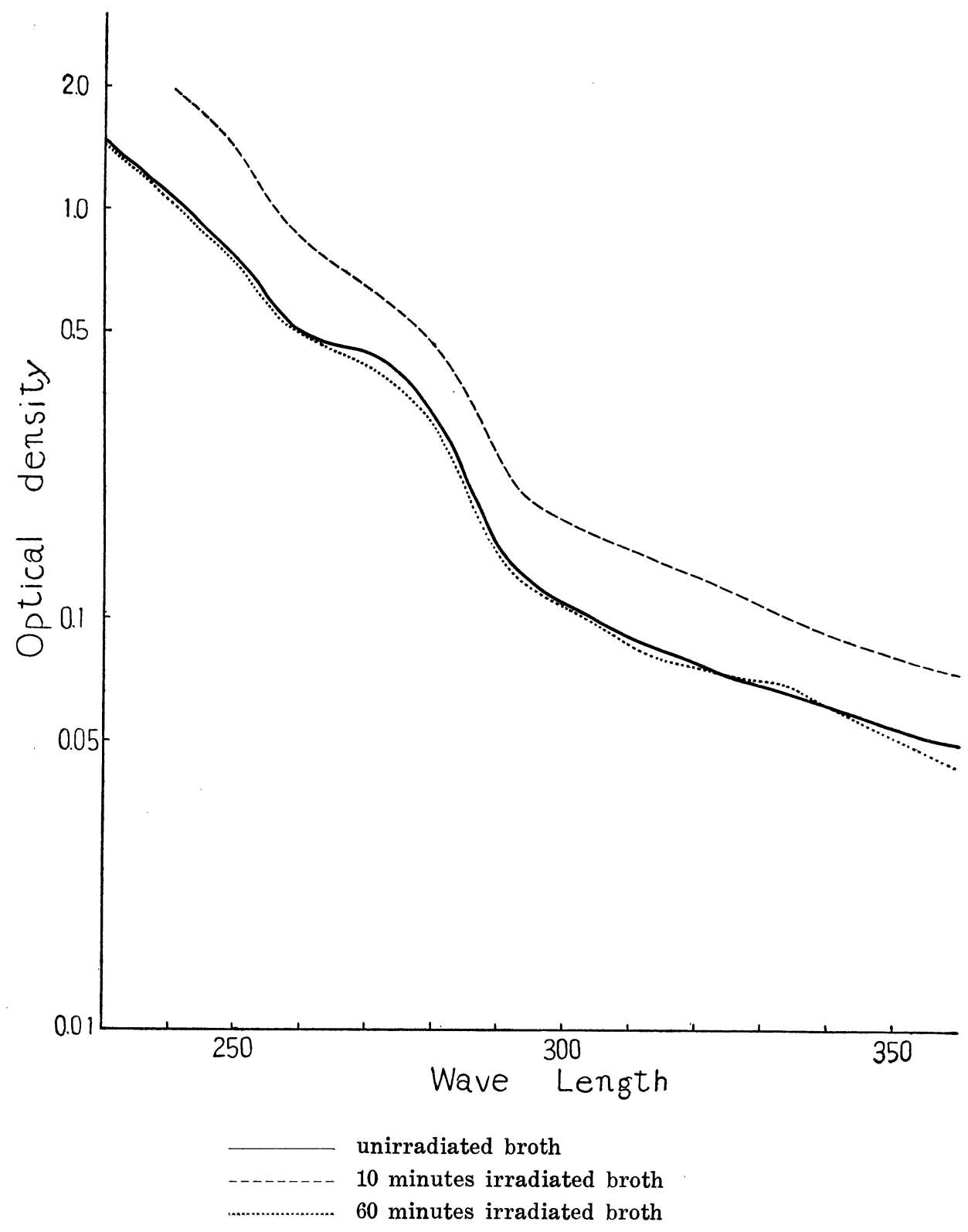


at an optical density 0.09 determined Coleman Jr. spectrophotometer (approximately 5 billion) was further diluted with physiological saline to $10^{-9}$ for use.

1. Changes produced in the broth by ultraviolet irradiation

Experiment: Under the condition specified above, the broth without mixed with the bacterial suspension was irradiated for 10 and 60 minutes. After irradiation, the optical density of each broth in a 1:100 dilution was determined by Beckman's spectrophotometer.

Findings: As shown in Fig. 1, no significant changes were observed.

2. Survival curve of $E$. coli in a broth suspension after ultraviolet irradiation

Experiment: Bacterial suspension in a quantity of $1 \mathrm{ml}$ was added into a quartz test tube containing the broth to obtain a dilution of $10^{-7}$.

The survival number of the bacteria in each test tube after irradiation for $2.5,5,7.5,10,20,30,45,60,100$ and 180 minutes was determined on thioglycolate medium by the most probable number table.

Finding: As shown in Fig. 2, the survival percent after irradiation for 10 minutes was extremely high being approximately 1.5 times as much as of the control. Decreasing step by step after this, it became the minimum of $50 \%$ after irradiation continued for 30 minutes. Then, the percentage began to rise again reaching approximately $75 \%$ of the control by the end of the irradiation continued for 45 minutes. Thereafter, the percentage decreased drawing nearly a straight line.

Fig. 2. Survival per cent of E. coli communis C-13 by ultraviolet irradiation

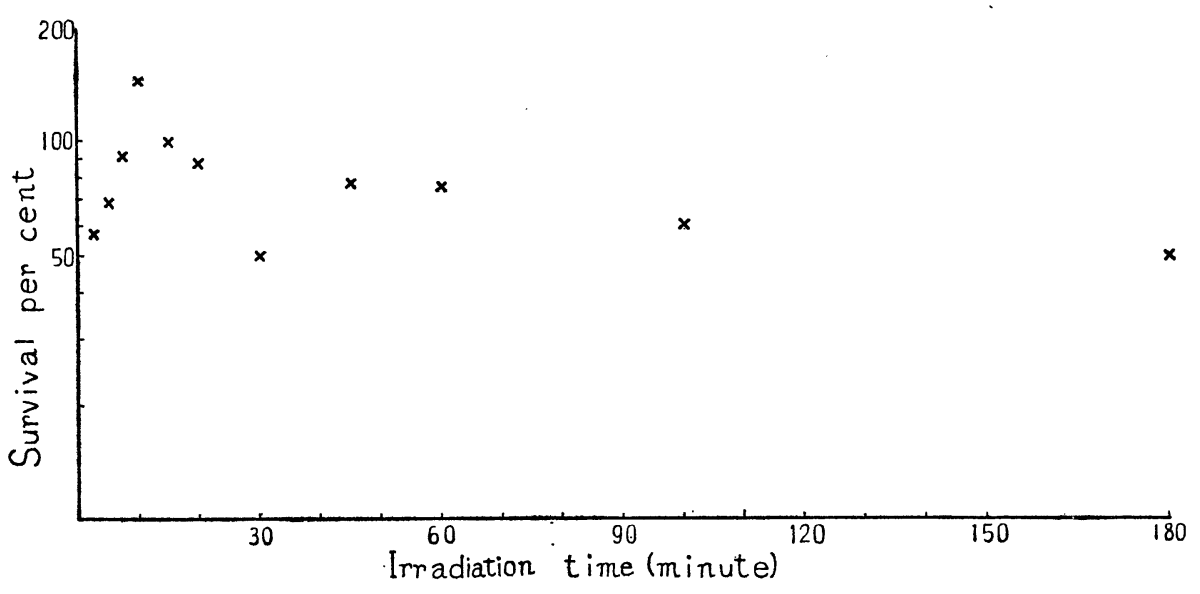


Fig. 3. Growth curves of ultraviolet light irradiated organism by turbidity method

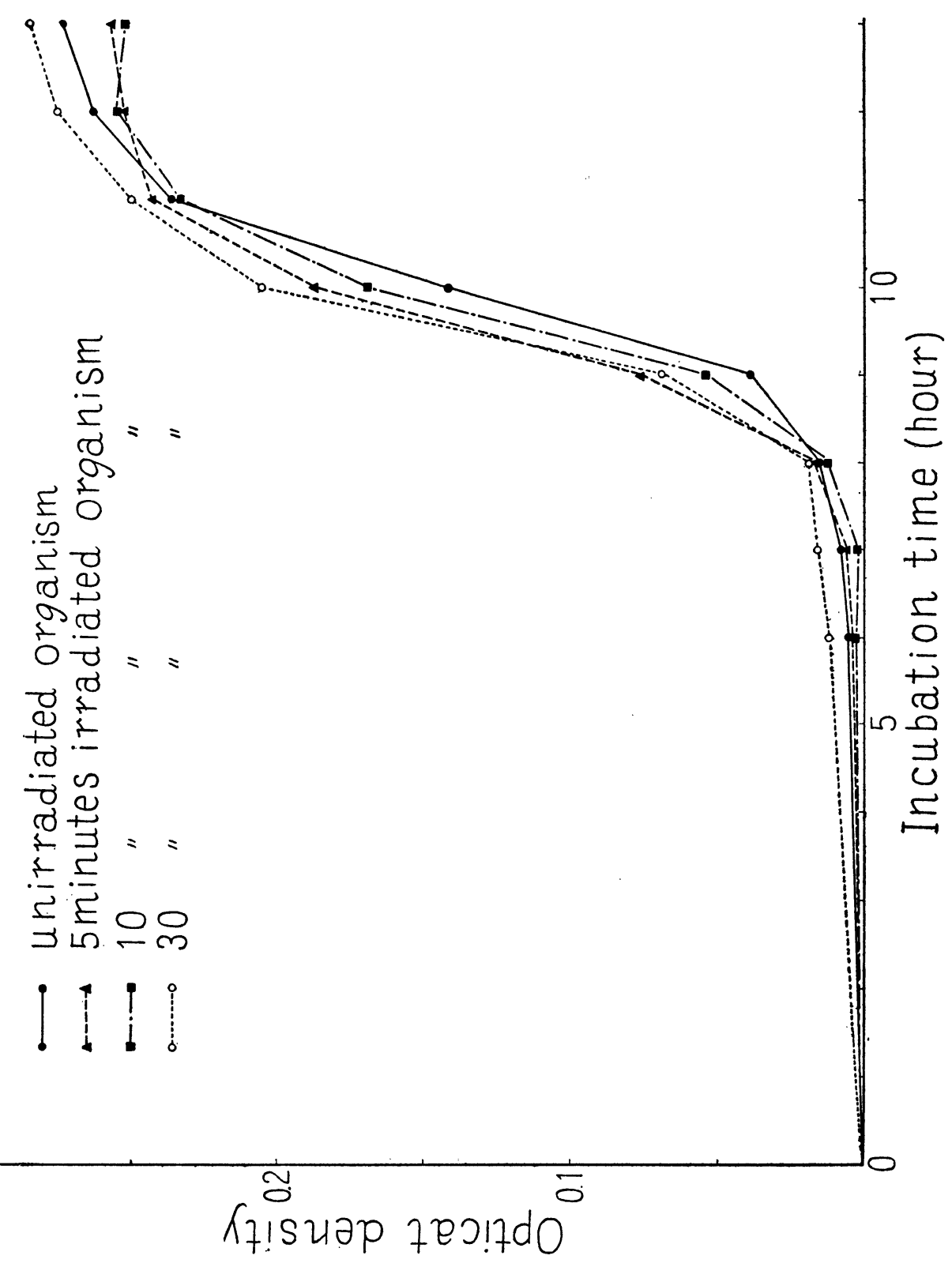


Fig. 4. Growth curves of ultraviolet light irradiated organism by colony count

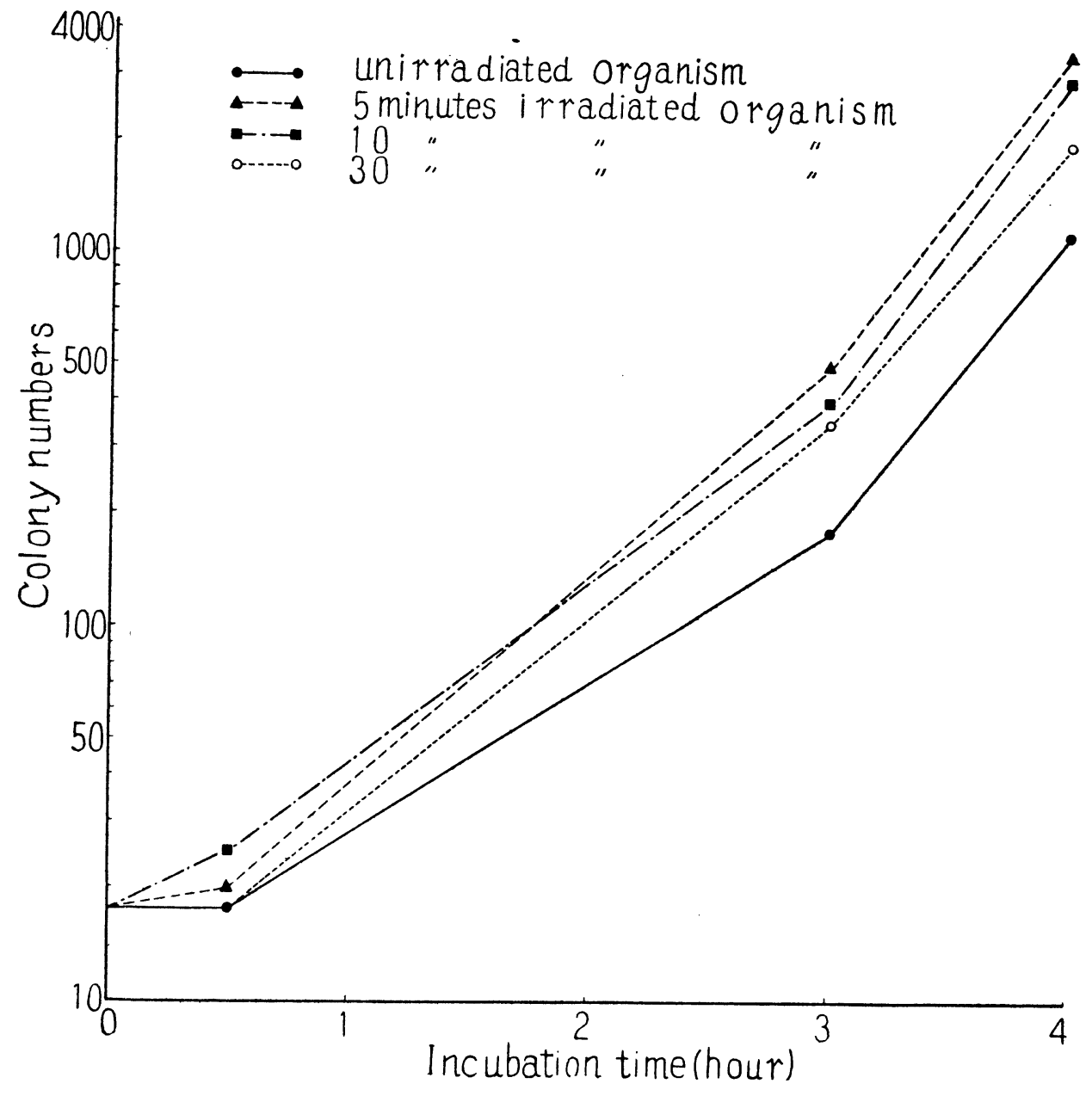


3. Growth of ultraviolet irradiated organisms

Experiment: The broth suspensions irradiated for different periods of 5, 10, and 30 minutes in Experiment 2, were incubated at $37^{\circ} \mathrm{C}$ and their growth curves were drawn by the optical density determined on Coleman Jr. spectrophotometer at the end of 6 to 13 hours after incubation (Fig. 3).

Further $0.1 \mathrm{ml}$ each of the above bacterial suspensions incubated for 3 to 4 hours was inoculated on agar plates for colony count (Fig. 4).

Findings: As shown in Figs. 3 and 4, the growth rate of survival organisms was equal to or even better than the control. Even the lowest survival percentage observed after 30 minutes of irradiation showed a much higher growth rate than the control.

4. Stainability and morphology of irradiated organisms

Experiment: The broth suspensions used in Experiment 2 were incubated at $37^{\circ} \mathrm{C}$ for 24 hours.

Findings: a. Changes in stainability. Regardless or the period of irradiation, all irradiated organisms were much harder to stain in the fuchsin of Gram stain than nonirradiated control. The stainability of irradiated organisms in the single fuchsin stain was, however, much better than the control.

b. Changes in morphology. No significant changes were produced in the morphology of the organisms in the suspensions irradiated for 2.5 to 7.5 minutes. Numerous swollen cells were observed, however, being mixed with a small number of the cells reduced in size on the contrary when irradiated for 10 minutes. Longer period of irradiation resulted in the increase of the number of the cells reduced in size. But, when cultured at $37^{\circ} \mathrm{C}$ for 24 hours in the same bouillon or on thioglycolate medium, those morphological changes disappeared.

\section{CONSIDERATIONS}

Downes, Blunt et $\mathbf{a l}^{6), 7)}$ have reported that the ultraviolet rays within the range of $2,600 \AA$ to $2,900 \AA$ which have the highest bactericidal activity are also the rays most efficient for causing coagulation of protein and further their bactericidal activity is not the indirect operation of hydrogen peroxide generated by irradiation but is the direct activity of radiated rays. Wyss ${ }^{8)}$ and Coblentz ${ }^{9}$ ) have also reported that the bactericidal activity of ultraviolet irradiation is not the influence of some toxic substance formed in the culture medium.

Regarding the coagulation of protein, $\mathrm{Mond}^{10)}$ et al attributed the reason why the colloidal state of the most of living bodies is influenced by short waved rays to the coagulation of protein due to the change in the electric charge of sol being influenced by photons emitted. Clark et al11) reported on the similar findings obtained from the experimental ultraviolet irradiation made on egg albumin. By an ultramicroscope, Addoms ${ }^{12}$ ) observed the coagulation of protein 
in the irradiated capillary roots of wheat, and this coagulation disappeared when the irradiation was discontinued.

When physiological saline was used as dispersion medium in our experiments, an irreversible coagulation took place immediately and completely as the result of the strong energy of irradiation, namely, the absorption of photons by micell, whereas, when broth was used as dispersion medium, the influence of ultraviolet irradiation being weakened, a reversible coagulation followed. This coagulation is that of the living colloid which includes bacterial membrane as stated by Downes and Blunt. Coagulation is the concentration protein micells and this coagulation will invite the death of bacterial cells. Further, Bancroft ${ }^{13}$ ) classified this coagulation into two different types of reversible coagulation and irreversible coagulation (the authors are of the opinion that, strictly speaking, there should not be two types of coagulation colloid-chemically and this reversible coagulation should be called as coaservation). Mond's theory and Addom's reversibility would easily be understood by the above explanation. Therefore, we can not consider this bactericidal activity of ultraviolet irradiation is due to the generation of hyprogen peroxide.

The survival curve after irradiation of 30 minutes showed a remarkable increase and thereafter decreased gradually. This decreasing curve resembled very much to that of the saline suspension, however, there was a difference in the tangent between those two curves. If the influence of ultraviolet irradiation on the broth was remarkable such survival curve could not be expected from the broth suspension.

Bancroft et al have observed a similar reversible coagulation took place in the yeast treated with same disinfectants. In addition, we ${ }^{14)}$ proved on the fish body (Salanx microdum, Bleeker) that this coagulation appeared first on the cellular surface as the result of the use of disinfectants or aneasthetica. Similar appearance of coagulation was also observed in the changes of the stainability of irradiated organisms.

Changes produced by irradiation in the electric charge of micells will develop the diminution of the distance between two micells resulting in the disturbance of their arrangement on the inner surface of the cells (hydrophilic colloid) and it is considered that a part of the excessive energy thus produces will change into the growth energy. The survival curve observed after 10 minutes of irradiation in Experiment 2 can be explained by the above mentioned explanation. When this explanation is done by using Coulom's equation, it will be as follows:

$$
F=\frac{1}{D} \cdot \frac{e}{r^{2}} \quad \begin{aligned}
e: & \text { electric charge of a micell } \\
r: & \text { distance between micells } \\
D: & \text { dielectric constant of water } \\
F: & \text { potential energy }
\end{aligned}
$$


As increase in the electric charge $e$ will cause the diminution of the distance $r$ resulting in the increase of the potential energy $F$. When the dielectric constant $D$ of the dispersion medium is minimized by irradiation, the potential energy $F$ will still be increased. The potential energy at this period, however, does not show any significant difference, so that, there appears an excess of the energy which will become the growth energy. It appears, further, that there exists a correlation between the amount of this excessive energy and the rise in the survival curve.

The above mentioned is the theoretical explanation of Arndt-Schultz law in which weak stimuli are given on the growth promoting stage (Bancroft).

In several experiments, the peak of this survival curve were found in the range of 10-30 minutes irradiation. Studies are undergoing, therefore, on the relation between the above mentioned excess energy and the promotion of bacterial growth by using purely chemical substances which absorb the ultraviolet portion of the spectrum.

In experiments made with another broth, further, are remarkable decrease in the survival rate, as seen after 30 minutes irradiation, was observed after the above mentioned promotion of bacterial growth. This decrease may due to the disposal of the too old and juvenile cells by irradiation. Even on this stage, as shown clearly in Figs 3 and 4, the priloferation of the irradiated cells was highly promoted.

Luckiesh ${ }^{15}$ ) has denied the presence of ultraviolet resistant organisms. But his irradiation was made on each successive transfer, so that, so far as the coagulation remained to be reversible it was quite natural that he failed to observe resistant organisms. On the contrary, we could evidently observe the proliferation of weakly ultraviolet-resistant organisms after irradiation continued for 45 minutes. Similar curve of the decrease in the survival rate observed before 2.5 minutes and the following increase up to 10 minutes of irradiation in Experiment 2 may suggest an increase in the number of ultraviolet-resistant organisms, but as there was not a single instance of the survival curve which showed a decrease before reaching its maximum, this particular increase in the survival percent is considered to be due to some other cause.

Our theory of disinfectant mentioned above can also be applied for the explanation of physiological influences. The change produced in the potential energy of micell, in other words, either the change in $D$ or $e$ by those agents will result in the inhibition or the killing of the organisms depending on the extent of this charge, namely, whether it is within the range of reversible or not. When the change produced in the potential energy of micell is extremely slight, however, the change will act as the growth promoting stimuli (ArndtSchultz Law).

For bactericidal purpose, it is necessary to cause the irreversible change which is so called a practical dilution in the case of disinfectants. The toxic 
effect of a ray is caused by the coagulation of protein colloid exactly in the same manner as that takes place in the case of chemical agents.

The authors wish to express their heart-felt gratitude for the cooperation rendered by the members of the Sterility Test Division of the National Institute of Health.

\section{REFERENCES}

1. Hollander A. and Claus W. D., 1936. J. gen. Physiol., 19, 753.

2. Lea. D. E., Haines R. B., and Coulson C. A. 1941. J. Hyg., 41, 1.

3. Hercik F. 1936. J. gen. Physiol., 20, 589.

4. a. Wyckoff R. W. G. 1930. J. exptl. Med., 52, 435.

b. Wyckoff R. W. G. 1930. J. exptl. Med., 52, 769.

5. Otani A. and Kobayashi S. unpublished

6. Downes and Blunt 1877. Proc. Roy. Soc., 26, 488.

7. Downes and Blunt Compt, rend. soc. Biol., 73, 323.

8. Wyss O., Clark J. B., and Stone W. S. 1949. J. Bact., 56, 51

9. Coblentz W. W. and Fulton H. R., 1924. Sci. Papers U. S. Bur. Standards 495., $19,641$.

10. Mond 1922. Archiv. ges. Physiol., 196, 540.

11. Clark 1922. Am. J. physiol., 61, 72.

12. Addoms 1927. Am. J. Botany., 14, 147.

13. Bancroft D. W. and Richter G. H. 1930. J. Physiol. Chem., 35, 215.

14. Masuyama T. May 29. 1952. Conference of the National Institute of Health of Japan and Institute of Infections Disease.

15. Luckiesh 1948. J. Bact. 55, 369. 